\title{
Immediate and Six-month Effects of Project EX Russia: A Smoking Cessation Intervention Pilot Program
}

\author{
Bulat Idrisov, $\mathrm{MD}^{1}$, Ping Sun, $\mathrm{PhD}^{2}$, Leila Akhmadeeva, $\mathrm{MD}, \mathrm{PhD}^{3}$, Thalida Em Arpawong, \\ $\mathrm{MPH}^{4}$, Polina Kukhareva, MS, $\mathbf{M P H}^{5}$, and Steve Sussman, $\mathbf{P h D}^{6}$ \\ ${ }^{1}$ Bashkortostan State Medical University, Pediatrics Department, 3 Lenina Street, Ufa, Russia, \\ 450008; bidrisov@gmail.com \\ 2University of Southern California, Department of Preventive Medicine, 2001 N. Soto Street, SSB \\ MC 9239, Los Angeles, CA 90032, USA; sping@usc.edu \\ ${ }^{3}$ Bashkortostan State Medical University, Department of Neurology, Neurosurgery and Medical \\ Genetics, 3 Lenina Street, Ufa, Russia, 450008; leila_ufa@mail.ru \\ ${ }^{4}$ University of Southern California, Department of Preventive Medicine, 2001 N. Soto Street, SSB \\ MC 9239, Los Angeles, CA 90032, USA; arpawong@usc.edu \\ ${ }^{5}$ University of North Carolina at Chapel Hill, Collaborative Studies Coordinating Center, $137 \mathrm{E}$. \\ Franklin Street, Suite 203, Chapel Hill, NC 27514, USA; kuhareva@live.unc.edu \\ ${ }^{6}$ University of Southern California, Departments of Preventive Medicine and Psychology, $2001 \mathrm{~N}$. \\ Soto Street, SSB Room 302A, Los Angeles, CA 90032, USA; ssussma@usc.edu
}

\section{Abstract}

This study evaluates the performance of the Project EX tobacco use cessation program in Russian summer recreational camps. An eight-session clinic-based tobacco use cessation program for adolescents was tested during the summer of 2011 in an experimental pilot trial that involved different youth that rotated through camps. Conditions were nested within camps. Two rotations of unique subject groups of smokers (program and standard care control) through each of five camps provided the means of controlling for campsite by condition. Assignment of condition by rotation was random (by a flip of a coin), achieving reasonable baseline comparability (total $n=164$ smokers at baseline, 76 program group, 88 standard care control group). Evaluation involved an immediate pretest and posttest and a six-month telephone follow-up. At immediate posttest, Project EX was moderately well-received, significantly reduced future smoking expectation (46\% reduction in EX Program Condition versus $8 \%$ in Control, $\mathrm{p}<.0001$ ), decreased intention to not quit smoking ( $-5.2 \%$ in EX versus $+1.4 \%$ in Control, $\mathrm{p}<.05$ ), and increased motivation to quit

\footnotetext{
(C) 2013 Elsevier Ltd. All rights reserved.

Correspondence to: Bulat Idrisov; Steve Sussman.

Publisher's Disclaimer: This is a PDF file of an unedited manuscript that has been accepted for publication. As a service to our customers we are providing this early version of the manuscript. The manuscript will undergo copyediting, typesetting, and review of the resulting proof before it is published in its final citable form. Please note that during the production process errors may be discovered which could affect the content, and all legal disclaimers that apply to the journal pertain.

Contributors

Authors B.I. and S.S. designed the study and wrote the protocol. Authors B.I. and L.A. secured support for the study and were involved in all aspects of the implementation. Author S.S. conducted literature searches and provided summaries of previous research studies. Author P.S. conducted the statistical analysis and wrote sections of the manuscript. Authors T.E.A. and P.K. wrote portions of and revised the manuscript. Authors B.I. and S.S. wrote the first draft of the manuscript and all authors contributed to and have approved the final manuscript.
}

Conflict of Interest

All authors declare that they have no conflicts of interest. 
smoking $(0.72$ versus $-0.04, \mathrm{p}<.0001)$. At the six-month follow-up, program subjects reported a higher intent-to-treat quit rate during the last 30 days $(7.5 \%$ versus $0.1 \%, \mathrm{p}<.05)$. For the subjects who remained monthly smokers at the six-month follow-up, Project EX reduced subjects' level of nicotine dependence $(-0.53$ versus $+0.15, \mathrm{p}<.001)$. The results were quite promising for this program, which included motivation enhancement, coping skill, and alternative medicine material. However, further research on teen tobacco use cessation programming in Russia with larger sample sizes, involving other locations of the country, and with stronger research designs is needed.

\section{Keywords}

Project EX; tobacco use cessation; experimental pilot design; summer camps; Russian Federation; Bashkortostan

\section{Introduction}

Tobacco use is the most prevalent and preventable lifestyle-related cause of death in the world (Fiore et al., 2000; Makomaski and Kaiserman, 2004). Unfortunately, tobacco users become addicted to nicotine within only a couple of years after initiation of use (Sussman \& Ames, 2008). A majority of young tobacco users (60-85\%) have made at least one quit attempt and failed (CDC, 2008; Sussman \& Black, 2009). Prevalence of smoking among Russian youth and adults is quite high. Up to one third of Russian youth have tried a cigarette by 10 years of age; $27 \%$ and $19 \%$ of 15 year old males and females, respectively, are current smokers; and up to $27 \%$ of high school youth are daily smokers depending on region sample and average age (Global Youth Tobacco Survey, 2009; Gunning et al., 2009; Sussman, Gufranova, \& Demin, 2007). Also, approximately $60 \%$ and $16 \%$ of adult males and females are current smokers (Global Youth Tobacco Survey, 2009; Sussman, Gufranova, \& Demin, 2007).

Tobacco use cessation program development research for youth is needed. Yet, relatively few studies of teen smoking cessation have been conducted and evaluated compared to adult cessation programs (Sussman \& Sun, 2009; Sussman, Sun, \& Dent, 2006), and only 25\% of these studies have been conducted outside the United States (Sussman, 2012). Of 64 controlled studies reviewed by Sussman and Sun (2009), 17 were completed outside of the U.S. Of these studies, four were from Australia, three were from Canada, one was from China, one was from Finland, two were from New Zealand, one was from Singapore, one was from Switzerland, and four were from the UK. Program minus control group effects were not found to differ as a function of being from within or outside the U.S. (Sussman \& Sun, 2009). Among the non-U.S. studies, seven were experimental, and 10 were quasiexperimental. Ten of the trials took place in a school-based clinic or classroom type setting, whereas three were community-wide, and two each were computer-based or medical clinics. Program contents were fairly evenly split between cognitive-behavioral, motivation, and social influence-focused. There was an average of 5.47 sessions (range $=2$ to 16). Four of the studies had fewer than 50 subjects, three had more than 50 but less than 200 subjects, and 10 had more than 200 subjects. These studies indicate a dire need for more well-controlled research trials of teen tobacco use cessation outside of the U.S. (particularly outside of English speaking countries), and suggest that such trials may be effective. However, at present there appear few treatment options outside of the U.S., particularly outside of the school setting.

The propagation of teen tobacco use cessation programs internationally is consistent with aims of the Framework Convention on Tobacco Control (FCTC; e.g., Sirichotiratana et al., 
2005; Sussman \& Black, 2010; Sussman, Pokhrel, et al., 2007; Warren et al., 2000). Along with other types of activities (e.g., mass media campaigns, policy regulations), wider use of evidence-based teen tobacco use cessation programming might help decrease the prevalence of tobacco use among Russian teens. To our knowledge there is only one published study on a tobacco use cessation program among teens in Russia (Aleksandrov et al., 2006). This was a single group study of 93 14-to-16 year olds. Adolescents from low income families received a six month-long cognitive-behavioral program, which included private psychological consultations, group psychotherapy, and electro-puncture (i.e., SelfControlled Energo Neuro Adaptive Regulation procedure or SCENAR, a biofeedback device developed originally for the Russian Space Program). Self-reported assessment of quitting was $19.4 \%$ at immediate posttest (also using a CO expired-air pipeline assessment to help validate reports). A total of 79 youth could be located at a 14 month follow-up, and $13.9 \%$ of them had quit smoking. Thus, the intent to treat quit rate at the follow-up was $11.8 \%$.

Project EX was developed in California, in the U.S., and is considered an evidence-based program at numerous agencies (e.g., Centers for Substance Abuse Prevention, National Cancer Institute, and Health Canada). Project EX was originally developed as an 8-session clinic-based tobacco use cessation program for adolescents. It provides motivation enhancement and cognitive-behavioral skills information, in ways enjoyable to teens to elicit quit attempts which may double rates compared to standard care (Sussman et al., 2004). While motivation instruction places an emphasis on helping youth "see through" the course of cessation, cognitive-behavioral skills place an emphasis on helping youth cope with physiological reactions and situations that are encountered while quitting (also see Milton et al., 2004).

Project EX recently has been used as a template for which to engage in international translation of teen tobacco use cessation (Sussman, 2012). Project EX pilot study work is ongoing in eight countries that have been approached thus far (Sussman, 2012). The program was implemented in Wuhan, China; Israel and partners; Bashkortostan, Russia; and Elche, Spain. Implementation is planned for Vienna, Austria; Mumbai, India; and was just completed in Bangkok, Thailand. This work will lead eventually to a greater understanding regarding preference for type of programming (e.g., clinic versus classroom modality), challenges in recruitment and retention, program receptivity, and short-term (approximately 3-month post-program) quit rates.

The first international pilot study completed was in Wuhan, China using a single-group multiple baseline design (Zheng et al., 2004). A self-report questionnaire was completed by $62210^{\text {th }}$ grade students (42\% boys) from two urban Wuhan schools in June, 2000. Smokers were identified. Approximately three weeks later the clinic program began and naturally occurring quitting could be observed in the interim. This quit rate was 3\% (i.e., two of 68 baseline smokers quit). Forty-five smokers became clinic participants, attended at least six of the clinic sessions, and completed the immediate posttest questionnaire. All 45 of these participants also completed the follow-up questionnaire, a mean of 4.6 months after the posttest ( $\mathrm{SD}=0.9$ months). The program was rated as very helpful; there was a $10.5 \%$ fivemonth follow-up intent-to-treat quit rate corrected for biochemical validation adjustment; 3.5-4.8 times the quit rate achieved prior to beginning of clinic. The Bashkortostan study is the second international pilot work of Project EX to reach completion.

The Bashkortostan Republic, in the Russian Federation, is one of the locations where Project EX recently has been piloted. Ongoing collaboration between University of Southern California and Bashkir State Medical University in Ufa, the Bashkortostan Republic, permitted the possibility of engaging in the translation of Project EX from the U.S. to the Russian Federation context. Bashkortostan is a republic in the Russian Federation spanning 
143,600 square kilometers ( $0.8 \%$ of the Russian territory) with a population of 4.1 million (2.7\% of the Russian population), and representing dozens of ethnicities (Shakurov, 1996). The capital city of Bashkortostan is Ufa, located near the Ural Mountains, with a population of a little over one million, making it the 11th highest populated city in Russia.

To our knowledge this is the first controlled trial of teen tobacco use cessation with sixmonth follow-up data conducted in the Russian Federation. We chose a summer camp setting for delivery of the smoking cessation programming. We chose this setting in part due to a matter of convenience for treatment delivery, where youth smokers may be easily reached and due to high receptivity of the camps to receiving such programming as a camp activity. Also, importantly, no previous teen tobacco use cessation program research study has been conducted at a summer camp setting. This study was conducted at summer recreational camps. There were five public summer camps that serve children and adolescents from Bashkortostan and nearby regions. Four out of five camps were located in Bashkortostan itself but one was in Krasnodar Krai in Tuapse, which is a seaport town situated on the northeast shore of the Black Sea, south of Gelendzhik and north of Sochi (population=63,292).

The present study describes the implementation and 6-month outcomes of Project EX at these camps. We hypothesized that Project EX would demonstrate a higher quit rate compared to standard care over a six-month follow-up period using an experimental design. Multiple groups of campers experience summer recreational camps over 21-to-30-day periods, depending on the camp. Two rotations of different youth through the same camps during the summer of 2011 permitted program and standard care control conditions nested within campsites.

\section{Method}

\subsection{Project EX Curriculum}

The Project EX clinic program involves eight sessions. During the first four sessions, students are prepared to strengthen their resolve to quit tobacco use. The second four sessions are focused on quit-attempts. The curriculum involves use of four talk show enactments of different smoking cessation issues (i.e., "family and friends confront smokers about their habit", "your cigarettes may be stressing you out", "quitting smoking: I've been there and it does get better", and "warning: waiting to quit smoking may be hazardous to your peace of mind"), four alternative medicine techniques ("healthy breathing", "yoga activity", "letting feelings pass" meditation activity, and a "relaxation activity"), a homework assignment in which smokers notice the effects of cigarette smoking on them, a competitive game about passive smoking ("is smoking on the menu?"), and tobacco consequences, and quit and maintenance strategies (e.g., coping). Smokers can make personal commitments to quit. The curriculum is described in more detail in Sussman, Dent, \& Lichtman (2001).

To adapt the curriculum to Bashkortostan, the curriculum was translated to Russian, by host country-certified bilingual translators. In addition to the language adaptation, characters in the talk shows were changed from American to host country names, monetary amounts were changed from dollars to Rubles in the curriculum (to discuss the cost of smoking), and tobacco consequences and policy facts were tailored to the Russian Federation.

\subsection{Training in Project EX}

Between April and May, 2011, all camp counselors who studied at the Camp Counselor Training Center "Perspectiva" were given the opportunity to become a volunteer facilitator of the Project EX program at their camps. Each class of counselors received a two-hour 
introductory lecture about Project EX. The purpose of the lecture was to familiarize counselors with the study and recruit them for volunteering as program facilitators. The lecture included a brief summary of the Project EX curriculum, its history, international translation in other countries, advantages of using the program, and the role of program facilitators. Those who were interested in implementing the program were invited to return to the training center for a complete training.

On a subsequent day, interested volunteers spent eight hours studying and practicing the eight sessions of Project EX, derived from the training originally provided to the trainer (B.I.) from the program developer (S.S.). The purpose of the training was to familiarize the facilitator with the program material and relatively complicated details of program delivery (e.g., yoga poses, how to conduct a "Tobacco Smokehouse" game), teach the facilitator to deliver the material with fidelity (as written), and encourage continued practice of program delivery. There were 22 counselors within each camp. Three-to-five counselors (9-23\% of all counselors) took the training and were certified upon completion of the program. There were 21 volunteer facilitators (by camp, there were $3,4,5,5$, and 4, respectively), of which two were male (from the last two camps). Among these facilitators, seven were ethnic Russian, four were Bashkir, three were Tatar, one was Chuvash, and six were mixed (Bashkir-Russian, Tatar-Russian, or Bashkir-Tatar). They all were in their final year of studies for degrees in education and psychology, at Bashkortostan State Pedagogic University and varied in age from 19 to 24 (mean=22). Each had previous experience delivering educational programs. Study investigators were involved in each step of program implementation at camps and were available by telephone consultations with facilitators and camp managers when needed.

\subsection{Standard Care Control}

Youth in the control condition received no formalized intervention classes, materials, or programs and were surveyed at each time point. Standard care approaches regarding tobacco use were followed in accordance with respective camp policies and traditions. Staff members were not responsible for oversight or advisement on smoking cessation for youth attending camps since counselors were focused on providing an environment of summer recreation and leisure time for attendees. However, tobacco use "officially" was not allowed at the camps such that smokers sometimes were punished by staff. While only occasionally enforced, when caught smoking, some smokers were scolded, had to do physical exercises such as jogging, had to hand over their cigarette packs, had to write a note of explanation, were told that their parents and school would be notified about their smoking, or were threatened with being sent home from the camp. Most of the time, smoking was overlooked as long as it was not engaged in openly.

\subsection{Recruitment of Subjects}

The availability of the clinic activity was announced by camp counselor-facilitators as a groups of youth arrived at camp. The program was considered an indoor activity in which smokers could participate. The activity was an alternative to unstructured time, and thus was preferred by tobacco users as a means to quit and as an interesting novel activity. Camp counselor-facilitators recruited teenage smokers in all camps. A snow ball sampling method was used to form groups in both program and control rotations. That is, adolescents who were known to be smokers were asked by their counselors, with whom they had developed trusting relationships, to bring their smoking friends to join the study. Inclusion criteria for participants were having smoked cigarettes in the last 30 days. As in Sussman, Dent, \& Lichtman (2001) smoking cigarettes even one time in any amount in the past 30 days would qualify to be involved in the study. Participants were excluded if they did not indicate themselves as smokers or did not express their interest in the program. Among the 164 
subjects who participated in the pretest survey, 142 (77 in control and 65 in program condition) completed the immediate posttest questionnaire (87.7\% retention rate), and 130 (70 in control and 60 in program condition) completed the longer term post-program questionnaires at the 6-month (80.3\% retention rate) follow-up.

\subsection{Research Design, Implementation, and Data Collection}

Implementation and/or immediate pretest/posttest data collection across the five camps occurred from June, 2011 to August, 2011. Each camp rotation was between 21 to 30 days in length. Each camp hosted both an EX Program Condition group and standard care Control Condition group during different times of the summer; in two camps the program group rotation came before the control group. The condition that came first was based on the flip of a coin; thus, the design is an experimental pilot trial. Youth in a given rotation were informed that they would be offered assistance in quitting smoking. However, they were kept blinded to study condition, which was easy considering that totally different cohorts of youth attended the different camp rotations.

Youth who were in the program condition received two to three Project EX classes per week led by a camp counselor who had been trained as a Project EX facilitator. Attendance at the sessions was encouraged by the counselors during indoor activity periods, and was approximately $95 \%$ across all sessions. Program delivery was consistent with another pilot study conducted in Wuhan, China (Zheng et al., 2004). Delivery of programming was in a private room, with only attendees and the facilitator. All sessions, and activities within sessions, were completed by facilitators. No reinvention of material was reported by any of the implementers to the trainer, and anecdotal observations of delivery by the facilitator at one session (arbitrarily selected) per camp suggested fidelity of delivery. The only drawback was that at three of the camps white boards or flipcharts were not available to assist with implementation.

Pretest surveys were collected one day prior to implementation of the first program session. The immediate posttest surveys were administered one day after completion of the eighth program session. The 6-month follow-up survey measures were collected from January through mid-February, 2012. Pretest and posttest surveys were administered to youth using a self-report, closed-ended response paper-and-pencil questionnaire over one class period at the camps. A majority of the 6-month follow-up data were collected from participants through telephone calls. For 20 subjects, from one of the camps across both conditions, the follow-up surveys were completed through electronic mail. Administrators were not provided information on program or control status of participants being surveyed. If a participant declined or did not respond to phone or e-mail requests to complete the sixmonth follow-up survey after more than ten invitations were made, she/he was considered lost-to-follow-up (and a continuing smoker, consistent with the intent-to-treat analysis assumptions).

\subsection{Questionnaire Measures}

Demographic items included age (in years), gender, ethnicity (coded as Bashkir, Russian, Tatar, Mixed, or Others [i.e., Chuvash, Chechen, or Armenian]), and current living situation (with one or both parents, alone, other). Descriptive smoking items, to gage level of smoking at pretest, included average daily smoking and whether the subjects smoked the day prior to taking the survey (Sussman, Dent, \& Lichtman, 2001).

In the process evaluation portion of the immediate posttest questionnaire, measures of student responsiveness to the program were obtained. The first measure assessed student's ratings of the program quality. Students were instructed to think about the program, 
including the topics and activities completed each day, and then form an opinion about the program with overall ratings on six items. These items asked the subject to rate the program on how much they "liked" and "learned" from it, how "informative" and "well-organized" it was, and how "enthusiastic" and "well-informed" the facilitator was. Responses were on 10point scales ("not at all" to "extremely"). As in previous work (e.g., Sussman, Dent, \& Lichtman, 2001), these adjectives were highly inter-correlated (Cronbach's $a=.80$ for the current study); thus ratings across the items were averaged to comprise a perceived program quality index. In the second measure, students rated how much they liked each of the key EX curriculum activities ( 8 total activities; from 1="terrible" to 9="excellent"). The activities included 1) Talk Show: Family and Friends Confront Smokers About Their Habit, 2) Talk Show: Cigarettes May be Stressing You Out, 3) Healthy Breathing, 4) Game: Is Smoking on the Menu?, 5) Talk show: Quitting Smoking: I've Been There and It Does Get Better, 6) Yoga, 7) Meditation, and 8) Talk Show: WARNING! Waiting to Quit Smoking may Be Hazardous to Your Peace of Mind.

Immediate posttest outcomes measures included next year future smoking expectation (e.g., Ramo, Prochaska, \& Myers, 2010; Sun et al., 2007), intention to ever quit smoking (e.g., Fagan et al., 2007), and motivation to quit smoking (e.g., McCuller et al., 2006). Future smoking expectation was assessed in the survey with the question "How likely is it that you will smoke cigarettes in the next 12 months? Would you say...," with 5 response categories ("1: definitely not", "2: probably not", "3: a little likely", "4: somewhat likely", and "5: very likely"); answers of anything other than "definitely not" was coded as susceptible to smoking. The intention to ever quit smoking was assessed with the item "Do you think you will ever quit smoking cigarettes?", with 4 response options ("1: Yes, I already have", "2: Yes, I will sometime in the future", "3: Yes, I will in the next few weeks", "4: Maybe", and "5: No"); a response of "No" was coded as having no intention to quit smoking. Motivation to quit smoking was assessed with three items, "How much energy (or effort, or desire) do you have to quit tobacco now and/or stay stopped?" with 4 point response options provided ("0: No", "1: A Little", "2: Some", and "3: A lot"). The Cronbach Coefficient Alpha for Motivation to quit smoking was 0.58 at pretest.

The outcome measures for six-month effects on behavior were last month (last 30-day) use of cigarettes and level of nicotine dependence among those that did not quit. Last Month cigarette smoking was assessed with the item asking "How many times have you used cigarettes in the last month (30 days) - or on an average day", with open-ended answers collecting times of smoking (e.g., Sussman, Dent, \& Lichtman, 2001). The level of nicotine dependence was assessed with the 8-item modified Fagerstrom Tolerance Questionnaire (mFTQ) (Chen et al., 2002; Prokhorov, 1996).

The correlations between pretest and posttest measures among the control subjects helps establish the reliability of the outcomes measures. The test-retest correlation between the two measures collected approximately 5 weeks apart was 0.78 for future smoking expectation, 0.84 for lack of intention to ever quit smoking, 0.74 for motivation to quit smoking, 0.91 for mFTQ score, and 0.82 for monthly smoking. These coefficients are very similar to previous work (Graham et al., 1984; Needle, McCubbin, Lorence \& Hochhauser, 1983; Sussman et al., 1995).

\subsection{Data Analysis}

Data analysis for program effects was completed by using a generalized mixed-linear model (Murray \& Hannan, 1990) using the SAS 9.3 statistical package (SAS Institute, 2011). Condition was considered a fixed effect variable; fixed at desired experimental levels (Camp). Camp was considered as a random factor. This specification allows for the statistical accounting of intra-class correlation within clustered units (campsite) for the 
logical generalization of findings beyond the specific sample. The variables evaluated in this analysis include three targeted immediate short-term outcomes assessed at posttest (future smoking expectation, intention to ever quit smoking, and motivation to quit smoking), and three smoking behavior outcomes assessed at the six-month follow-up (number of times cigarette smoking during the last 30 days; status of cigarette smoking during the last 30 days [yes or no], and scores for mFTQ for self-reported nicotine dependence level). The variables adjusted for in the analyses included campsite, age, gender, ethnicity, the outcome assessed at pretest, and a propensity for attrition score at immediate posttest or six-month follow-up. The propensity for attrition score was calculated from a model predicting the actual attrition status with pretest measures (Berger, 2005). The pretest measures in the attrition propensity prediction models included age, gender, ethnicity, whether or not live with both parents, camp, program condition, intention to not quit smoking, future smoking expectation, motivation to quit, last 30-day cigarette smoking, and mFTQ for self-reported nicotine dependence level.

\section{Results}

\subsection{Participants}

Pretest subjects varied from 13 to 19 years of age (mean age $=16.7$ years, $\mathrm{SD}=1.7$ years). The sample was $52.5 \%$ male; $32.7 \%$ Russian, $17.9 \%$ Tatar, $22.8 \%$ Bashkir, $19.1 \%$ mixed Russian with Tartar or Bashkir, and 7.4\% others (Chuvash, Chechen, or Armenian). Further, $37.0 \%$ of the students lived with both parents. All subjects reported to have smoked in last 30 days. The average daily smoking was between $1-21$ cigarettes per day (mean=6.5); approximately $94.4 \%$ also reported to have smoked the day before the pretest survey date. At pretest, $86.4 \%$ of the students reported that they may smoke in the next 12 months, though only $6.8 \%$ of the subjects expressed that they will not quit smoking cigarettes.

\subsection{Assessment of Attrition Bias at Posttest and Six-month Follow-up}

To assess the potential sampling bias due to attrition at the posttest or at six-month followup, comparisons were made of the sample that was lost at posttest $(n=22)$ to the analysis sample for effects at posttest $(\mathrm{n}=142)$; or the sample that was lost at six-month follow-up $(n=34)$ to the analysis sample for six-month effects $(n=130)$. The comparisons were made on nine key variables assessed at pretest. Measures included: age, gender, ethnicity, living with both parents or not, future smoking expectation, intention to ever quit smoking, motivation to quit smoking, number of times of 30-day cigarette smoking, and mFTQ nicotine dependence level. The comparisons utilized chi-square tests or t-tests to indicate statistically significant differences (two-tailed $\mathrm{p}$ \0.05). All nine variables were comparable at immediate posttest. However, at the 6-month follow-up, three variables were found to be significantly different across attrition status. The retained sample included fewer boys ( $48 \%$ versus $69 \%, \mathrm{p}=0.04$ ), fewer subjects living with both parents (33\% versus $53 \%, \mathrm{p}=0.04$ ), and self-reported lower frequency of last 30-day cigarette smoking (141 versus 182 times, $\mathrm{p}=0.05$ ). Thus, the analysis sample roughly approximated a random sub-sample of pretest subjects at the camps at immediate posttest and six-month follow-up, though the program effect analyses might have needed to statistically control for a few covariates (thus the calculation of propensity for attrition scores).

The retention rate did not differ for the EX condition (program versus control) across the immediate posttest and six-month follow-up assessments. At the posttest survey, retention was $89 \%$ in the control group, and $87 \%$ in the program group $(\mathrm{p}=0.72$ control versus program). At the six-month follow-up survey, retention was $80 \%$ in the control group and $81 \%$ in the program group ( $\mathrm{p}=0.93$ control versus program). Also, the afore-mentioned nine 
key variables were all statistically comparable between control and program conditions (i.e., all $\mathrm{ps}>0.05)$.

\subsection{Program Effects at Immediate Posttest}

The average overall program process quality rating was 6.98 (moderately high perception of program quality). The average likeability item score across all program activities was 6.53 (moderately likeable). The highest average activity likeability score (6.8) was for "Talk Show: Cigarettes May be Stressing You Out", and the lowest score (6.4) was for "Healthy Breathing".

The program outcome effects at immediate posttest were evaluated with three outcomes: next year future smoking expectation, lack of intention to ever quit smoking, and motivation to quit smoking. As shown in Table 1, the EX program significantly reduced future smoking expectation (46\% reduction in the Program Condition versus $8 \%$ in the Control Condition, $\mathrm{p}<.0001)$, reduced lack of intention to quit smoking ( $-5.2 \%$ in the Program Condition versus $+1.4 \%$ in the Control Condition, $\mathrm{p}<0.05$ ), and enhanced motivation to quit smoking ( 0.72 in the Program Condition versus -0.04 in the Control Condition, $\mathrm{p}<0.0001$ ).

\subsection{Program Effects at Six-month Follow-up}

The EX program successfully generated statistically significant positive effect on all three outcomes at six-month follow-up. As shown in Table 2, compared with the Control Condition subjects, the Program Condition subjects reported a fewer number times cigarette smoking during the last 30 days $(-10.7$ versus $+29.8, \mathrm{p}<0.05)$; and a higher quit rate for smoking during the last 30 days $(7.5 \%$ versus $0.1 \%, \mathrm{p}<0.05)$. Furthermore, for the subjects who remained monthly smokers at the 6-month follow-up, the EX program successfully reduced subjects' level of nicotine dependence $(-0.53$ versus $+0.15, \mathrm{p}<0.001)$.

\section{Discussion}

With high rates of teenage smoking in Russia, the need for evidence-based tobacco use cessation programs is clear. Few studies on tobacco use cessation for teens exist outside of the U.S. and no previous controlled trials have been completed in Russia. The success of program implementation and positive outcomes on diminishing smoking behaviors at both immediate posttest and six-month follow-up for this pilot study suggests that Project EX may be a promising curriculum for wider spread implementation among Russian youth.

One novelty of implementing Project EX among teens in this study was the setting -use of summer recreational camps, which has not been attempted previously in other parts of the world (Sussman, 2012; Sussman \& Sun, 2009). Serendipitously, the summer camp institutions were flexible and staff interest provided a supportive partnership for implementing this study. Because of the high interest and need for a tobacco cessation program like EX, the Camp Counselor Training Center "Perspectiva" offered assistance for all aspects of implementation of the program at the camps. The absence of any standardized approach for smoking cessation at camps that participated in our study reinforces the potential for institutionalization of evidence-based youth tobacco cessation programming at Russian summer camps. Anecdotally, camp officials appreciated the program and expressed their interest to continue to implement Project EX. Currently we are working with the Training Center "Perspectiva" to implement the training again next summer. The fact that youth provided ratings of the program that were moderately favorable also suggests the potential for continuing to use Project EX in the future in this setting.

Most teen tobacco use cessation work has been completed in schools (Sussman \& Sun, 2009). However, in Bashkortostan, anecdotally, when approached, school facilities were 
more resistant to making accommodations for the organizational part of this program (e.g., using classroom time, taking the time and resources for training teachers as facilitators, gaining school administrative support, and needing classroom space for implementation of sessions). In the near future, investigators may develop a more collaborative approach to facilitate testing of Project EX in Russian high schools. For example, one of the study investigators was recently invited to be a part of an expert panel on eradicating tobacco smoking at schools in two nearby towns in Bashkortostan. Preliminary results of the present study were presented and Project EX was identified as an optimal strategy for school use. Indeed, increasing public support for youth smoking cessation, evidence that predictors of cigarette smoking are very similar in the U.S. and in Russia among high school age youth (Gunning et al., 2009), and findings that Project EX has been an effective cessation program in U.S. high school samples (Sussman et al., 2004; Sussman et al., 2007; Sussman, Dent \& Lichtman, 2001), along with the current cessation results at Russian camps, may all help lead to near-future implementation of replication studies on Project EX in Russian high schools.

\subsection{Limitations and Future Research}

Further research on teen tobacco use cessation programming in Russia is needed with larger sample sizes, in other regions of the country, and with a greater number of randomized units. Despite there being reasonable sample equivalence between participants in the program and control conditions on pretest characteristics in this study, there may have been unmeasured confounders that contributed to the study results. For example those who chose to participate in the Project EX program condition may have had more peer support for quitting tobacco, as youth tended to bring in their friends to the quit groups.

Also, it is possible that in the camp setting, EX participants received more consistent encouragement to quit from camp counselors (particularly who doubled as EX facilitators) in addition to the program sessions. In that case, program effects might have been overestimated. Conversely, camp counselors who also served as Program Condition facilitators may have been unable to refrain from discouraging youth in the Control Condition from smoking given their EX training. In the latter case, program effects may have been underestimated. In any case, future evaluation of Project EX could be strengthened by inclusion of additional assessments on the fidelity of program delivery.

Another limitation is that there is scant data on the demographic composition of youth who attend these camps. Thus, it is impossible to say whether or not the participants are representative of camp attendees or, more accurately, camp attendees who are smokers. Data from one recent study of 365 high school teens from Bashkortostan (Gunning et al., 2009) suggests that the proportion of males who attended the clinics (52.5\%) was higher than the proportion of teenage males at high schools in general (45\%). In addition, the percentage Tartar representation was lower (17.9\% versus $31.4 \%$ ) and Bashkir representation was higher (19.1\% versus $8.8 \%$ ); otherwise, ethnicity was reflective of Bashkortostan high school youth.

One other limitation is that the snow-ball method of recruitment precludes greater generalizability of results because friendship networks of smokers were selected in both conditions. Certainly, the ability to generalize these results to other teens is limited without more information on camp attendees who chose not to participate in Project EX. Because data on cigarette smoking and demographic characteristics were not measured among students who did not participate in the study, generalizability of the findings is limited to a population with pretest measurement access restrictions like those experienced in this study (i.e., absentee and refusal mechanisms). Possibly a more systematic protocol of recruitment would have led to a greater representation of the universe of smokers in the camps. 
Strength for interpretation of the current results is derived from the fact that equivalence was obtained on all outcome-related variables across the two conditions. However, there are other limitations of this study such as a potential response-demand effect. Even with the assurance of confidentiality of survey responses, participants may have felt subjective pressure to respond to survey items favorably (i.e., toward quitting). Response demands could have impacted both conditions, certainly, though perhaps inclusion of cessation programming could have added more pressure to report having quit tobacco use regardless of program contents.

Future trials may be strengthened by the use of biochemical validation of nicotine use (e.g. salivary cotinine strips; e.g., Chen et al, 2002). To the best of our knowledge it is possible that an $11 \%$ decrease in reporting of abstinence could occur as a function of use of biochemical validation (Sussman, Dent, \& Lichtman, 2001). For example, with use of CO biochemical validation Sussman, Dent, \& Lichtman (2001) found abstinence rates to decrease from $19 \%$ to $17 \%$ in the program condition and $10 \%$ to $8 \%$ in the control condition. The relative difference across program and control conditions was maintained. One difficulty with using biochemical validation is that it is voluntary in research studies. Thus, a bias could occur in estimating over-reporting of abstinence, produced by persons willing or not willing to engage in biochemical validation protocol. Simple responses such as in this study are likely to be reasonably accurate (see Sussman et al., 1995).

Future research should include learning about the characteristics of youth that benefit most from a smoking cessation program delivered in Bashkortostan summer recreational camps. Importantly, future research may be able to discern mediators and moderators of program effects achieved by Project EX in the Russian Federation. Motivation enhancement to quit is a likely mediator, consistent with the immediate posttest data and the one Project EX mediation study conducted in the U.S. (McCuller et al., 2006). We also speculate that quitting skills (e.g., withdrawal symptom coping strategies, methods of quitting) may also mediate program effects though future research is needed to examine that possibility. There may be the potential to compare motivational enhancement versus withdrawal skills coping constituents of programming in future component analysis studies, and we speculate that the same comparisons are likely to replicate across the U.S. and Russian Federation context.

Regarding moderation, we speculate that possibly subjects' demographic information (age, gender, ethnicity), or dispositional attributes may moderate program impact. For this study, age, gender, ethnicity, and the outcome assessed at baseline was not found to moderate intervention effects on the outcomes at six-month follow-up. However, in one tobacco use prevention study conducted in China, a comorbidity between depression and smoking was found to moderate the intervention effect among regular middle school students (Sun et al, 2007).

Another need, future studies might assess use of other tobacco products in Russia. For example, while almost all tobacco use among youth in Russia is through cigarette smoking (Global Youth Tobacco Survey, 2009), marketing of other products such as cigars and hookah pipes is aggressively occurring (e.g., http://www.russiatab.com/; accessed on 11-7-2012).

\subsection{Conclusion}

In summary, there have been no evidence-based approaches previously evaluated in Russian settings for adolescent smoking cessation. Project EX demonstrates that a cessation program which includes sessions on motivation enhancement (e.g., talk shows), stress-coping strategies including mindfulness (e.g., yoga, meditation), discusses consequences of smoking to self and others in a game format, and utilizes summer recreational camp 
counselors as smoking cessation facilitators can be used as an effective tobacco use intervention for youth in Russia.

\section{Acknowledgments}

We would like to thank the Camp Counselor Training Center "Perspectiva" for permitting us to engage five camps in this study, with camp counselors serving as group facilitators. We also would like to thank Artur Yamalov who volunteered and donated his time to data entry for this research.

\section{Role of Funding Sources}

This manuscript was supported in part by a grant from the National Institute on Drug Abuse (NIDA; Grant \#DA020138). NIDA had no role in the study design, collection, analysis or interpretation of the data, writing the manuscript, or the decision to submit the paper for publication.

\section{References}

Aleksandrov AA, Kotova MB, Rozanov VB, Klimovich VYU, Vaganov AD. Secondary prevention of smoking among adolescents is an important way of reducing the frequency of smoking in the adult population. Profilactika Zabolevani i Ukreplenie Zdorovia [Disease Prevention and Health Promotion]. 2006; 6:36-38.

Berger VW. The reverse propensity score to detect selection bias and correct for baseline imbalances. Statistics in Medicine. 2005; 24:2777-2787. [PubMed: 15981305]

Centers for Disease Control and Prevention (CDC). Global Youth Tobacco Surveillance, 2000-2007. Morbidity and Mortality Weekly Reports. 2008; 57(SS01):1-21. from http://www.cdc.gov/mmwr/ preview/mmwrhtml/ss5701a1.htm.

Chen X, Zheng H, Sussman S, Gong J, Stacy A, Xia J, Gallaher P, Dent C, Azen S, Shan J, Unger JB, Johnson CA. Use of the Fagerstrom Tolerance Questionnaire for measuring nicotine dependence among adolescent smokers in China: A pilot test. Psychology of Addictive Behaviors. 2002; 16:260-263. [PubMed: 12236462]

Fagan P, Auguston E, Backinger CL, O’Connell ME, Vollinger RE, Kaufman A, Gibson JT. Quit attempts and intention to quit cigarette smoking among young adults in the United States. American Journal of Public Health. 2007; 97:1412-1420. [PubMed: 17600244]

Fiore, MC.; Jaen, CR.; Baker, TB.; Bailey, WC.; Benowitz, NL.; Curry, SJ.; Wewers, ME. Treating tobacco use and dependence: 2008 update. Rockville, MD: US department of health and human services. Public Health Service; 2008. Clinical practice guideline.

Global Adult Tobacco Survey (GATS). GATS: Russian Federation. Moscow: Ministry of Health and Social Development of the Russian Federation and partners; 2009. http://www.who.int/tobacco/ surveillance/en_tfi_gats_russian_countryreport.pdf [accessed 11-7-2012]

Graham JW, Flay BR, Johnson CA, Hansen WB, Grossman LM, Sobel JL. Reliability of self-report measures of drug use in prevention research: Evaluation of the Project SMART questionnaire via the test-retest reliability matrix. Journal of Drug Education. 1984; 14:175-193. [PubMed: 6536737]

Gunning M, Sussman S, Rohrbach LA, Kniazev V, Masagutov R. Concurrent predictors of cigarette and alcohol use among U.S. and Russian adolescents. Journal of Drug Education. 2009; 39:385400. [PubMed: 20443454]

Makomaski IEM, Kaiserman MJ. Mortality attributable to tobacco use in canada and its regions, 1998. Canadian Journal of Public Health. 2004; 95:38-44. [PubMed: 14768740]

McCuller WJ, Sussman S, Wapner M, Dent C, Weiss DJ. Motivation to quit as a mediator of tobacco cessation among at-risk youth. Addictive Behaviors. 2006; 31:880-888. [PubMed: 16139963]

Milton, MH.; Maule, CO.; Yee, SL.; Backinger, C.; Malarcher, AM.; Husten, CG. Youth tobacco cessation: A guide for making informed decisions. Atlanta: U.S. Department of Health and Human Services, Centers for Disease Control and Prevention; 2004.

Murray DM, Hannan PJ. Planning for the appropriate analysis in school-based drug abuse prevention studies. Journal of Consulting and Clinical Psychology. 1990; 58:458-468. [PubMed: 2212183] 
Needle R, McCubbin H, Lorence J, Hochhauser M. Reliability and validity of adolescent self-reported drug use in a family-based study: a methodological report. International Journal of the Addictions. 1983; 18:901-912. [PubMed: 6605944]

Prokhorov AV, Pallonen UE, Fava JL, Ding L, Niaura R. Measuring nicotine dependence among highrisk adolescent smokers. Addictive Behaviors. 1996; 21:117-127. [PubMed: 8729713]

Ramo DE, Prochaska JJ, Myers MG. Intentions to quit smoking among youth in substance abuse treatment. Drug and Alcohol Dependence. 2010; 106:48-51. [PubMed: 19699041]

SAS Institute, Inc. SAS release 9.3. Cary, North Carolina: SAS Institute, Inc; 2011.

Shakurov, RZ. Bashkortostan: A short encyclopedia. Ufa, Russia: Scientific Publishing; 1996.

Sirichotiratana, N.; Techatraisakdi, C.; Sujirarat, D.; Rahman, K.; Warren, CW.; Jones, NR.; Asma, S.; Lee, J. Linking Global Youth Tobacco Survey (GYTS) data to the WHO Framework Convention on Tobacco Control: The case for Thailand. Bangkok, Thailand: Report for WHO-Southeast Asia Regional Office; 2005.

Sun P, Miyano J, Rohrbach LA, Dent CW, Sussman S. Short-term effects of Project EX-4: A classroom-based smoking prevention and cessation intervention program. Addictive Behaviors. 2007; 32:342-350. [PubMed: 16820267]

Sun P, Unger JB, Guo Q, Gong J, Ma H, Palmer PH, Chou C-P, Li Y, Sussman S, Ritt-Olson A, Xiao L, Johnson CA. Comorbidity between depression and smoking moderates the effect of a smoking prevention program among boys in China. Nicotine \& Tobacco Research. 2007; 9:S599-S609. [PubMed: 18067035]

Sussman S. International translation of Project EX: A teen tobacco use cessation program. SUCHT. 2012; 58:317-325.

Sussman, S.; Ames, SL. Drug abuse: Concepts, prevention and cessation. New York, N.Y: Cambridge University Press, 2008; 2008.

Sussman S, Black DS. Advancing youth tobacco use cessation in developing countries: Practical considerations. International Public Health Journal. 2009; 1:119-128.

Sussman, S.; Dent, CW.; Burton, D.; Stacy, AW.; Flay, BR. Developing school-based tobacco use prevention and cessation programs. Thousand Oaks: Sage Publications, Inc; 1995.

Sussman S, Dent CW, Lichtman KL. Project EX: Outcomes of a teen smoking cessation program. Addictive Behaviors. 2001; 26:425-438. [PubMed: 11436934]

Sussman S, Gufranova U, Demin A. Speculation about options for teen tobacco use cessation in the Russian Federation. Tobacco Induced Diseases. 2007; 3:1-15. [PubMed: 19570299]

Sussman, S.; McCuller, WJ.; Zheng, H.; Pfingston, YM.; Miyano, J.; Dent, CW. Tobacco Induced Diseases. Vol. 2. Project EX: A program of empirical research on adolescent tobacco use cessation; 2004. p. 119-132.

Sussman S, Pokhrel P, Black D, Kohrman M, Hamann S, Vateesatokit P, Nsimba SED. Tobacco control in developing countries: Tanzania, Nepal, China, and Thailand as examples. Nicotine \& Tobacco Research. 2007; 9(S1):S447-S457. [PubMed: 17978974]

Sussman S, Sun P. Youth tobacco use cessation: 2008 update. Tobacco Induced Diseases. 2009; 5:3. [PubMed: 19183452]

Sussman S, Sun P, Dent CW. A meta-analysis of teen tobacco use cessation. Health Psychology. 2006; 25:549-557. [PubMed: 17014271]

Warren CW, Riley L, Asma S, Eriksen MP, Green L, Blanton C, Loo C, Batchelor S, Yach D. Tobacco use by youth: a surveillance report from the Global Youth Tobacco Survey project. Bulletin of the World Health Organization. 2000; 78:868-876. [PubMed: 10994259]

Zheng H, Sussman S, Chen X, Wang Y, Xia J, Gong J, Liu C, Shan J, Unger J, Johnson CA. Project EX - A teen smoking cessation initial study in Wuhan, China. Addictive Behaviors. 2004; 29:1725-1733. [PubMed: 15530717] 


\section{Highlights}

- We evaluated a Project EX tobacco use cessation program in Russian summer camps.

- The experimental pilot trial among teens included 3 data collection points $(n=164)$.

- At immediate posttest, Project EX increased motivation to quit smoking.

- At 6-months, higher quit rates were found in the intervention vs. control group.

- At 6-months, reduced nicotine dependence was found in intervention vs. control. 
Table 1

Immediate Posttest Program Effects ${ }^{a}$

\begin{tabular}{|l|c|c|c|}
\hline Outcome & $\begin{array}{c}\text { Control }(\mathbf{N}=77) \\
\text { posttest }- \text { pretest } \\
\Delta \pm \mathbf{s e}\end{array}$ & $\begin{array}{c}\frac{\text { Program }(\mathbf{N}=\mathbf{6 5})}{\text { posttest - pretest }} \\
\Delta \pm \mathbf{s e}\end{array}$ & $\begin{array}{c}\text { Net Effect } \\
\text { posttest - pretest } \\
\Delta \pm \mathbf{s e}\end{array}$ \\
\hline $\begin{array}{l}\text { Future Smoking } \\
\text { Expectation (\%) }\end{array}$ & $-8.2 \pm 4.8^{+}$ & $-46.0 \pm 5.2^{* * * * *}$ & $-37.8 \pm 6.8^{* * * *}$ \\
\hline $\begin{array}{l}\text { Intention Not to Ever } \\
\text { Quit Smoking (\%) }\end{array}$ & $1.4 \pm 2.4$ & $-5.2 \pm 2.5 *$ & $-6.6 \pm 3.0^{*}$ \\
\hline $\begin{array}{l}\text { Motivation to Quit } \\
\text { Smoking }\end{array}$ & $-0.04 \pm 0.05$ & $0.72 \pm 0.06^{* * * * *}$ & $0.76 \pm 0.08^{* * * *}$ \\
\hline
\end{tabular}

Notes:

${ }^{a}$ Multi-level random coefficients modeling is conducted, assuming a random Camp effect and a fixed program effect. Adjusted for pretest measure of the outcome, age, gender, ethnicity, and propensity for attrition at posttest.

Designation for $\mathrm{p}$ values:

$+\mathrm{p}<0.10$

$\mathrm{p}<0.05$;

*****

$\mathrm{p}<0.0001$ 
Table 2

Six-month Follow-up Program Effects on Cigarette Smoking ${ }^{a}$

\begin{tabular}{|c|c|c|c|}
\hline Outcome & $\begin{array}{c}\text { Control }(\mathrm{N}=70) \\
\text { 6-Month - pretest } \\
\Delta \pm \mathrm{se}\end{array}$ & $\frac{\text { Program }(\mathrm{N}=60)}{\text { 6-Month - pretest }} \underset{\Delta \pm \mathrm{se}}{ }$ & $\begin{array}{c}\text { Net Effect } \\
\text { Program - } \\
\text { Control } \\
\Delta \pm \text { se }\end{array}$ \\
\hline \multicolumn{4}{|l|}{ 30-day Cigarette Use } \\
\hline Times of use & $29.8 \pm 11.7$ * & $-10.7 \pm 12.5$ & $-40.5 \pm 15.9^{*}$ \\
\hline Quit rate (\%) & $0.1 \pm 2.7$ & $7.5 \pm 2.9 *$ & $7.4 \pm 3.7 *$ \\
\hline $\begin{array}{l}\text { mFTQ Nicotine } \\
\text { Dependence Score } b\end{array}$ & $0.16 \pm 0.16$ & $-0.53 \pm 0.17$ **** & $-0.69 \pm 0.20$ *** \\
\hline
\end{tabular}

Notes:

a Multi-level random coefficients modeling is conducted, assuming a random Camp effect and a fixed program effect. Adjusted for pretest measure of the outcome, age, gender, ethnicity, and propensity for attrition at posttest.

Designation for $\mathrm{p}$ values:

${ }^{+} \mathrm{p}<0.10$;

p $<0.05$;

**

$\mathrm{p}<0.01$;

$* * *$

$\mathrm{p}<0.001$;

p $<0.0001$

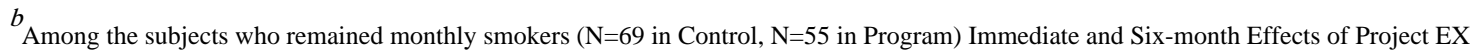
Russia: A Smoking Cessation Intervention Pilot Program 